\title{
Nonthermal plasma activates catalyst: from current understanding and future prospects
}

\author{
H.-H. Kim ${ }^{\mathrm{a}}$ and A. Ogata \\ National Institute of Advanced Industrial Science and Technology (AIST), 16-1 Onogawa, Tsukuba Ibaraki 305-8569, Japan
}

Received: 3 November 2010 / Accepted: 14 January 2011

Published online 21 July 2011 - (C) EDP Sciences

\begin{abstract}
Combination of two old-yet-new technologies (plasma and catalyst) is getting attentions for the advanced processes in 21 century. This paper reports the complementary combination of atmospheric pressure nonthermal plasma with catalyst for the air pollution control application. The most important feature of this complementary combination is that plasma enables catalyst to work even at room temperature. Up-to-date data on catalyst screening for the cycled system will be given in terms of enhancement factor and adsorption capacity. Visual observation using ICCD camera was applied to study how discharge plasma interacts with catalyst at atmospheric-pressure and ambient temperature.
\end{abstract}

\section{Introduction}

Plasma and catalyst processes have a centuries-old history both in academic study and practical use. Catalytic reaction has long been used as one of key processes in many chemical processes. Haber-Bosch process for $\mathrm{NH}_{3}$ synthesis is an early example of industrial scale application (the beginning of 1900s) of catalytic reaction. In $1923 \mathrm{FT}$ (Fischer-Tropsch) process was developed to convert gas mixture into liquid fuel, which is also referred to as gasto-liquid (GTL) process. The FT process is still in use in the fuel process using biomass. Catalyst is also indispensable for car industry; three-way catalyst, $\mathrm{NO} x$-storage catalytic reduction and DPF (diesel particulate filter). The importance of catalyst is still gathering attentions in nextgeneration industry such as nano-material synthesis, renewable energy (biomass) and fuel-cell. It has many mature markets, while still exploring new applications. On the other hand, plasma-involved commercial market is much less, but its growing rate is much larger than that of catalytic process. Environmental application of plasma also has a long history, but its area was limited mostly to ozone synthesis and its application. In recent years, the application areas of plasma are further expanding rapidly; for example, pollution control, semiconductor manufacturing, chemical and material synthesis, surface treatment, drinking- and waste water treatment, sterilization, and medical application. In this regards, these two processes can be referred to as "Old-Yet-New Technology". At the same time, they are still expected to play a key role in many cutting edge technologies such as nanotechnology, next generation energy (biomass, hydrogen and fuel cell),

\footnotetext{
a e-mail: hyun-ha.kim@aist.go.jp
}

optical use including plasma display panel, environment, and biomedical science.

When it comes to air pollution control, catalytic process has a long history of practical use in car exhaust gas cleaning, selective catalytic reduction process (SCR) of NO $x$ and VOC oxidation in chemical industries. The bottleneck of catalytic process is the high operation temperature usually up to several hundred ${ }^{\circ} \mathrm{C}$, where the catalysts exhibit proper activity. On the other hand, one important merit of nonthermal plasma is low operation temperature. The key feature of the combination lies on the activation of catalyst by the plasma at low temperature. In spite of the limited information on the working mechanism, many synergistic effects have been reported by many research groups. Figure 1 summarizes three key factors required for plasma processing of VOCs. Decomposition of VOCs has been started in 1990s in many countries. Except for alkanes (saturated hydrocarbon) plasma was found to destroy a variety of VOCs. Despite many noticeable achievements in terms of decomposition efficiency, some critical problems have been raised for the commercial use of plasma technology. One is the reduction of energy consumption. The other one is the suppression of unwanted byproducts. Especially, these requirements must be satisfied together with the removal efficiency before the industrial applications. If one of these requirements is not satisfied, the NTP process may lose its potential for the commercial use. As a smart way to solve those problems, the combination of plasma and catalyst has been proposed. The combination is divided into single-stage and two-stage depending of the position of catalyst. Plasmadriven catalyst (PDC) combines plasma and catalyst in a single-stage configuration. Two important features of the combination are high selectivity of catalyst and high reactivity of plasma at low temperature. Catalysts are directly 


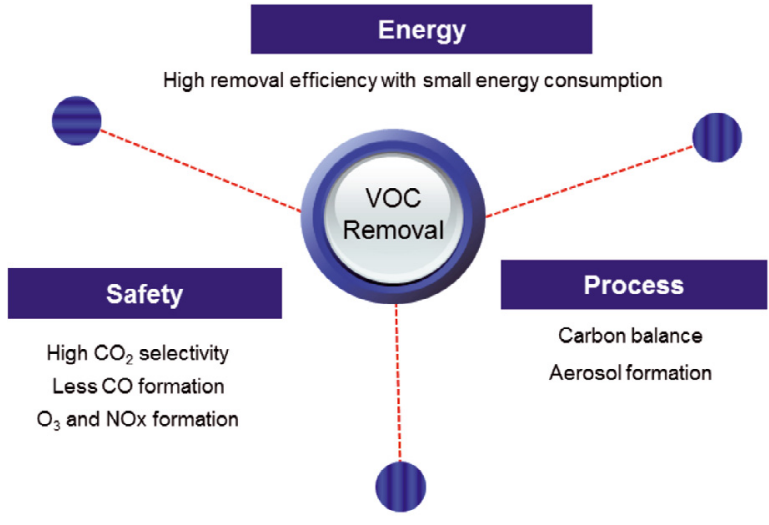

Fig. 1. Three key factors in plasma decomposition of volatile organic compounds (VOCs).

placed within plasma zone. This complementary combination provides some breakthrough of NTP alone process in various aspects. The understanding of the interaction between plasma and catalyst is still in early stage due mostly to the lack in fundamental information.

This work reports the current progress on the interaction of nonthermal plasma with catalyst and its application to VOC removal. The basic characteristics, the expected merits and current R\&D status will be overviewed. An interesting effect of catalyst-packing on the generation of discharge plasma was studied by using microscopeICCD camera.

\section{Early development}

Langmuir, Nobel laureate in chemistry (1932), is wellknown that he first coined plasma as technical term describing the ionized gas mixture. The other important work done by Langmuir is the formulation of gas adsorption on surface, which is now known as Langmuir isothermal adsorption equation. This approach opened a way for the kinetic calculation of catalytic reaction. It may be no exaggeration to say that he stands on the contact point of plasma and catalyst.

One of early studies in the surface chemical reactions under the influence of discharge plasma may date back to the ozone generation using electrical discharge coronas. Although being qualitative, Anderegg reported the influence of reactor materials on the corona discharge and ozone formation as well [1]. For given reactor configuration and applied voltage, resulting ozone concentration from corona discharge changed drastically according to the type of metal wires used as corona electrode. Newsome reported that the degree in ozone suppression was in the order of $\mathrm{Al}>\mathrm{Ag}>\mathrm{Au}>\mathrm{Cu}[2]$, but the effect varied considerably with time. Later this aging effect was is found to be the result of surface oxidation phenomena. Similar catalytic effect of corona electrode was also reported by Davidson et al. for silver and copper in positive corona discharge [3]. In recent years Yehia and Mizuno studied six electrode materials (silver, tungsten, gold, copper, nickel, and aluminum) and found that ozone suppression by silver was most prominent [4]. Furthermore the effect of silver was more prominent in positive corona in dry air than negative polarity or in oxygen. More recently, Petrov et al. reported nanocrystal formation on the surface of copper that has been exposed to a negative corona (Trichel pulse) discharge [5]. It is not clear how does it form and how this nanocrystal interacts with corona plasma, but it remains challenging area. The main drawbacks in using bulk material as catalyst are the small surface area and the amount used. The smaller the size of metals, the larger the effective reaction sites, and resulting in the enhancement of catalytic reaction. In most cases, the active metals are supported on the surface of substrates (such as $\gamma-\mathrm{Al}_{2} \mathrm{O}_{3}$, zeolite, activated carbon) having large surface area.

Combination of plasma with catalyst has been studied sporadically in time and space. One of important landmark in the single-stage plasma-catalyst system may the US patent by Henis in 1976 [6]. He proposed a singlestage plasma-catalyst reactor for NOx removal. The system was tested at $100{ }^{\circ} \mathrm{C}$ and the reactor was filled with various catalysts such as $\mathrm{Al}_{2} \mathrm{O}_{3}$, zirconium, silicate, cobalt oxide, thoria $\left(\mathrm{ThO}_{2}\right)$, activated carbon, molecular sieve, silica gel. Although the removal efficiency was not high due probably to the absence of reducing chemicals, this patent obviously went ahead of the times.

The combination of plasma with catalyst became popular in the late 1990s. The limitation of the plasma alone process has prompted combination of nonthermal plasma with other techniques including catalyst. Most of recent studies including some commercialized facilities adopt the combined process of NTP and catalyst.

\section{Experimental}

\subsection{Plasma reactor}

Plasma-driven catalyst (PDC) reactor packed with various catalysts was made of quartz tube and stainless steel wire for dielectric barrier and high voltage electrode, respectively. The details on the reactor are given in the previous paper [7], so only a brief description will be given here. Chemical activities of the catalysts were tested using a cylindrical barrier discharge reactor. A stainless steel coil (0.45 $\mathrm{mm}$ in diameter) was set in a quartz tube as a discharge electrode and silver paste was painted on the outer wall of the tube as a ground electrode. Gas flow rates were measured using mass flow controllers (Kofloc Co., FCC-3000). Benzene and toluene were used as model VOC and their concentrations were adjusted by changing the bubbling flow rate or the temperature-controlled water bath. A Fourier transform infra red (FTIR, Perkin Elmer Spectrum One) spectrometer was used for the determination of both VOC and products. One important advantage of FTIR gas analysis over the well-established gas chromatography method (GC) is that it does not interfere with ozone. In the case of GC analysis, coexisting ozone in the sample gas may cause additional decomposition of VOCs in an injection port and a column, resulting 
H.-H. Kim and A. Ogata: Nonthermal plasma activates catalyst: from current understanding and future prospects

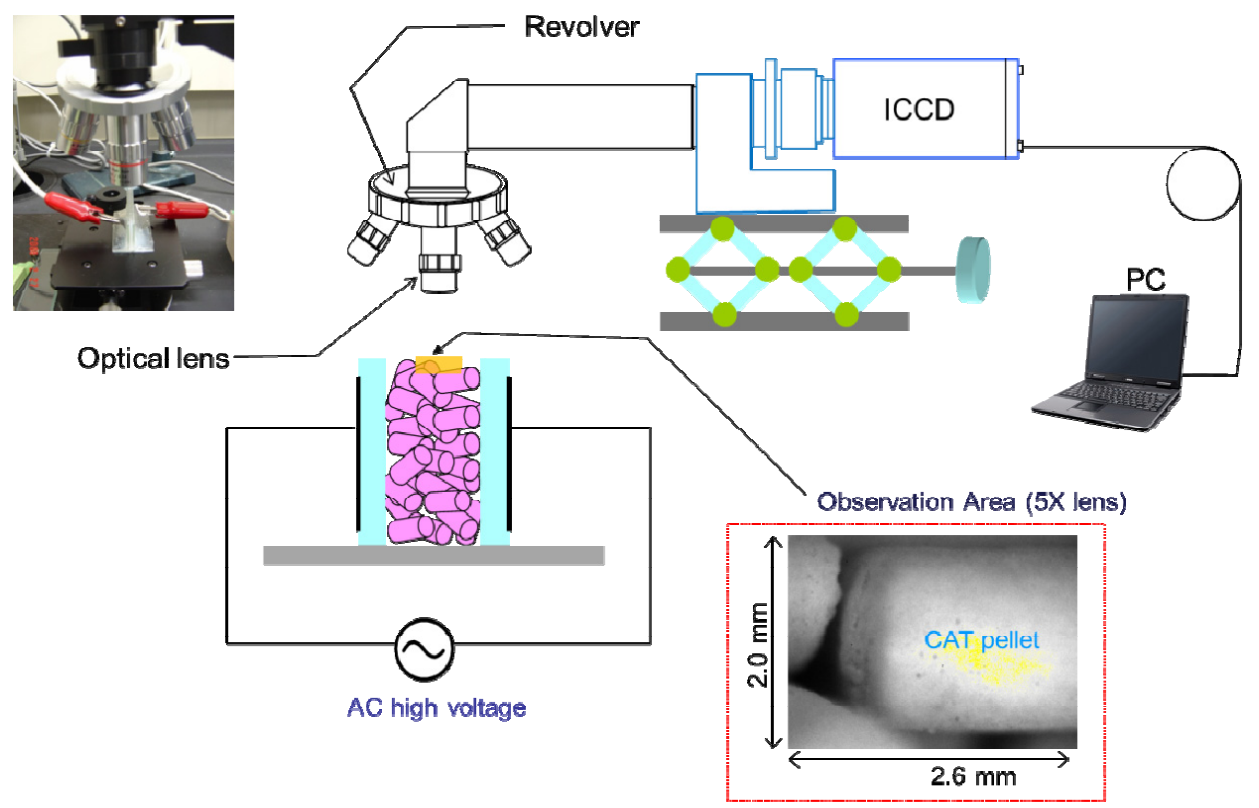

Fig. 2. Microscope-ICCD camera system for the observation of discharge plasma on the catalyst surface.

in the overestimation of decomposition efficiency. A timebase software (Perkin Elmer Ver 2.0) was used for the continuous measurement of gas concentration at $2 \mathrm{~min}$ intervals by averaging five scans with the wavenumber resolution of $1 \mathrm{~cm}^{-1}$. Power measurement is an important parameter in evaluating the performance of plasma reactor. In this work, Lissajous figure software (Insight Co., Lissajous Ver 1.72) was used to measure discharge power $\left(P_{\text {dis }}\right.$ in watt) and to calculate specific input energy (SIE in $\mathrm{J} \mathrm{L}^{-1}$ ). SIE, the ratio of input energy to unit gas flow rate, is calculated by the following equation

$$
\mathrm{SIE}=\frac{P_{d i s}}{Q_{f}}=\frac{\text { discharge power }(\mathrm{W})}{\text { gas flow rate }(\mathrm{L} / \mathrm{min})} \times 60 \text {. }
$$

\subsection{Catalyst}

Table 1 summarizes the properties of catalysts used in this study. Zeolites pellets used in this study had a diameter of about $1.6 \mathrm{~mm}$ and length of about 2.0-6.0 $\mathrm{mm}$. Silver nanoparticles were supported on the surface of zeolites by an impregnation method using $\mathrm{AgNO}_{3}$ as precursor substance. After several drying processes, the catalysts were calcined at $500{ }^{\circ} \mathrm{C}$ in air for $10 \mathrm{~h}$. The high-silica Y (HSY) zeolite has $\mathrm{Si} / \mathrm{Al}$ ratio of 12 before being extruded into pellet.

\subsection{Observation of discharge plasma on the catalyst surface}

Figure 2 shows the schematic diagram of observation system setup. A plate-type DBD reactor was set on a XY stage. The DBD reactor was made of two glass plates with $4 \mathrm{~mm}$ separation. Aluminum tapes were attached to the outer sides of the dielectrics, which serve as electrodes. ICCD camera (Hamamatsu Photonics) was used for the observation of surface plasma. Four optical lenses (Mitutoyo, MPlan Apo series) with different magnification were attached to the revolver. The observation area can easily be changed according to the condition. In the case of $5 \mathrm{X}$ lens $(2.0 \mathrm{~mm} \times 2.6 \mathrm{~mm})$, it is possible to observe the discharge plasma over single catalyst pellet.

\section{Results and discussion}

\subsection{Energy-dependent process: PDC}

Specific input energy is an important parameter in plasma chemical reaction. There are many different operating parameters in plasma reactor such as applied voltage, type of power supply, reactor type, and frequency and so on. For a given reactor, the overall chemical changes are proportional to the specific input energy. In the case of ozone generation, increasing voltage or frequency produces higher ozone concentration. On the other hand, these trends fall onto a single line when they are plotted in terms of SIE $[8,9]$. This energy-dependent behavior of plasma chemical reaction has been reported for many gas-phase reactions such as $\mathrm{NO}$ reduction in $\mathrm{N}_{2}$ [10], $\mathrm{NO}$ oxidation in dry air [11,12], removal of propane/propene [13]. Figure 3 shows the influence of gas flow rate on the toluene removal. Under this condition, no chemical reactions occurred in the absence of plasma. In the case of $2 \mathrm{wt} \% \mathrm{Ag} / \mathrm{TiO}_{2}$ catalyst, the numbers of PDC reactor were 1,3 and 8 for 5 LPM, 50 LPM and 100 LPM, respectively. Despite the difference in space velocity (flow rate or number of reactors) the similar decomposition efficiency of toluene was obtained for the flow rate ranges from 5 LPM to 100 LPM. The similar results were also reported for the decomposition of benzene by varying space velocity by a factor 
The European Physical Journal Applied Physics

Table 1. Catalysts used in this study.

\begin{tabular}{|c|c|c|c|c|c|c|}
\hline Catalyst & $\mathrm{TiO}_{2}$ & MOR & MS-13X & $\mathrm{NaY}$ & HSY & HY \\
\hline $\begin{array}{c}\text { Metal } \\
\text { loading }\end{array}$ & $\begin{array}{c}\mathrm{Ag} \\
(2 \mathrm{wt} \%)\end{array}$ & $\begin{array}{c}\mathrm{Ag}, \mathrm{Cu}, \mathrm{Zr} \\
(5,10,15 \mathrm{wt} \%)\end{array}$ & $\begin{array}{c}\mathrm{Ag}, \mathrm{Cu}, \mathrm{Zr} \\
(5,10,15 \\
\text { wt\%) }\end{array}$ & $\begin{array}{c}\mathrm{Ag} \\
(10 \mathrm{wt} \%)\end{array}$ & $\begin{array}{c}\mathrm{Ag} \\
(10 \mathrm{wt} \%)\end{array}$ & $\begin{array}{c}\mathrm{Ag}, \mathrm{Cu}, \mathrm{Zr} \\
(5,10,15 \\
\text { wt\%) }\end{array}$ \\
\hline \multicolumn{7}{|l|}{ Shape } \\
\hline Size & $1.8 \mathrm{~mm}$ & $\begin{array}{c}\phi 1.6 \mathrm{~mm} \times \sim 6 \\
\mathrm{~mm}\end{array}$ & $\begin{array}{c}\phi 1.6 \mathrm{~mm} \times \sim 6 \\
\mathrm{~mm}\end{array}$ & $\begin{array}{c}\phi 1.6 \mathrm{~mm} \times \sim 6 \\
\mathrm{~mm}\end{array}$ & $\begin{array}{c}\phi 1.6 \mathrm{~mm} \times \sim 6 \\
\mathrm{~mm}\end{array}$ & $\begin{array}{c}\phi 1.6 \mathrm{~mm} \times \sim 6 \\
\mathrm{~mm}\end{array}$ \\
\hline $\begin{array}{c}\text { BET } \\
\text { surface area } \\
\left(\mathrm{m}^{2} / \mathrm{g}\right)\end{array}$ & 59 & 380 & 540 & 750 & 690 & 520 \\
\hline Binder & $\begin{array}{l}\text { Alumina } \\
20 \mathrm{wt} \%\end{array}$ & $\begin{array}{l}\text { Alumina } \\
20 \mathrm{wt} \%\end{array}$ & $\begin{array}{l}\text { Alumina } \\
20 \mathrm{wt} \%\end{array}$ & $\begin{array}{l}\text { Alumina } \\
20 \mathrm{wt} \%\end{array}$ & $\begin{array}{l}\text { Alumina } \\
20 \mathrm{wt} \%\end{array}$ & $\begin{array}{l}\text { Alumina } \\
20 \mathrm{wt} \%\end{array}$ \\
\hline
\end{tabular}

* BET (Brunauer-Emmett-Teller).

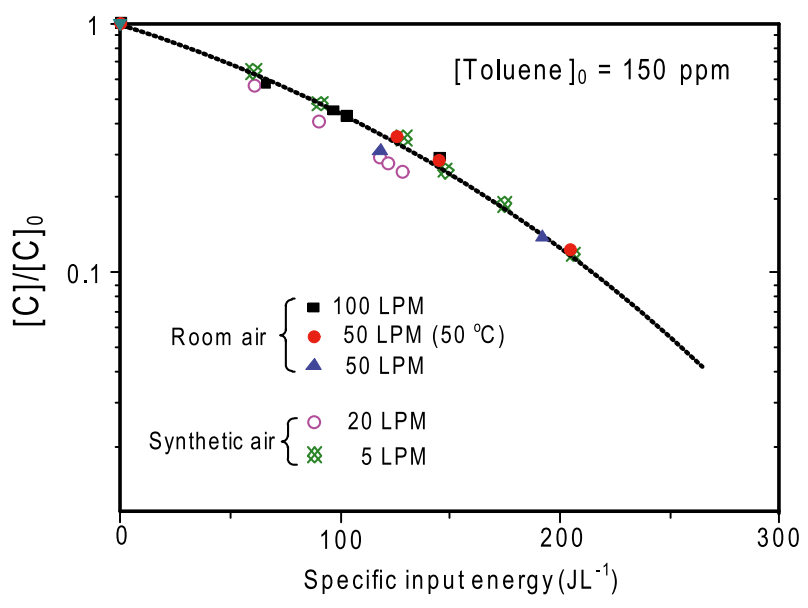

Fig. 3. Energy-dependent properties of plasma-driven catalysis. Decomposition of $150 \mathrm{ppm}$ toluene at $100{ }^{\circ} \mathrm{C}$ unless otherwise noted. In the test of $100 \mathrm{~L} \mathrm{~min}^{-1}\left(S V=65000 \mathrm{~h}^{-1}\right), 8$ reactors were connected in parallel.

of 5 [14]. These results supported that plasma provides a driving force in activating the catalysts.

As mentioned in Section 2, the basic way to enhance catalytic performance is to find proper combination of active metal and substrate. There have been extensive studies on the heterogeneous catalytic oxidation of VOC for several decades. Especially noble metals such as $\mathrm{Pt}$ and $\mathrm{Pd}$ have been found to be very effective in the total oxidation of VOC even at relatively lower temperature compared to the other metals [15]. One of the key factors in catalytic reaction is the area of active sites on surface. The surface area of metal catalyst, usually defined by BET area, can be easily enhanced by decreasing its size or increasing the loading amount. As illustrated in Figure 4 the smaller the size the larger the surface area of active metals for a given amount of use. Considering the cost problem, it is

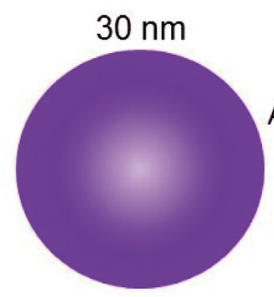

As size becomes smaller

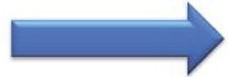

Surface area increases more than 30 times

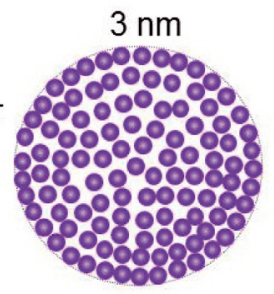

Fig. 4. The important size effect of metal nanoparticles.

desirable to make smaller the size of active metals supported on the surface of substrates $\left(\mathrm{TiO}_{2}, \gamma-\mathrm{Al}_{2} \mathrm{O}_{3}\right.$ and zeolite). For given amount of active metals, for example, reducing the size from $30 \mathrm{~nm}$ to $3 \mathrm{~nm}$ results in an increase of total surface area by 30 times. In other words, much less amount of metal will be necessary to get a certain surface area of active metals. Another important advantage in using metal nanoparticles is to lower the total usage of metals, which is normally expensive precious metals.

\subsection{NO $x$ dilemma in nonthermal plasma decomposition of VOC}

Figure 5 shows the NOx dilemma in the plasma process and diesel engine. In diesel engine, the formation of $\mathrm{NO} x$ is primarily a function of temperature, which is called as thermal $\mathrm{NO} x$. Engine operation at low temperature reduces thermal $\mathrm{NO} x$, but it is counterbalanced by the enhanced emission of particulate matter (PM). On the other hand, input energy determines the $\mathrm{NO} x$ emission in plasma process. Since the plasma decomposition of VOC is basically energy-dependent process, higher energy input leads to a higher decomposition of VOC and a large formation of $\mathrm{NO} x$ as well. It is unavoidable to produce nitrogen oxide during the plasma processing in air-like 
H.-H. Kim and A. Ogata: Nonthermal plasma activates catalyst: from current understanding and future prospects

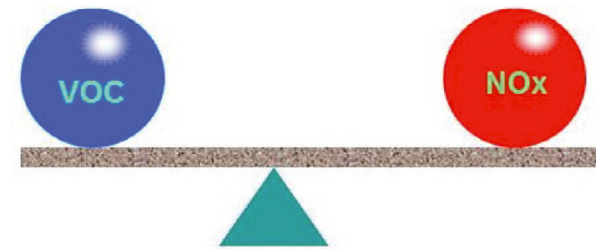

(a)

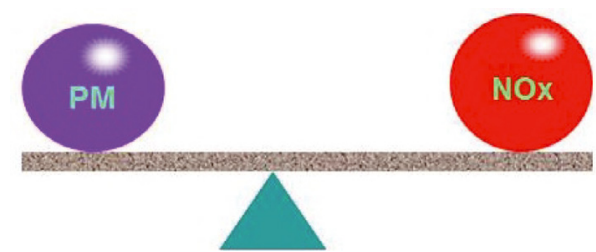

(b)

Fig. 5. NOx dilemma in nonthermal plasma processing of VOC and diesel engine. (a) Plasma process. (b) Diesel engine.

gas mixtures [16]. The observed $\mathrm{N}_{x} \mathrm{O}_{y}$ in plasma process includes $\mathrm{NO}, \mathrm{NO}_{2}, \mathrm{~N}_{2} \mathrm{O}_{5}, \mathrm{HNO}_{2}, \mathrm{HNO}_{3}$, peroxyacetyl nitrate $\left(\mathrm{PAN}, \mathrm{CH}_{3} \mathrm{COOONO}\right.$ ), methyl nitrate and methyl nitrite [17]. Except for in-situ measurement, NO is easily oxidized to $\mathrm{NO}_{2}$ by ozone so it is usually not detected in the presence of $\mathrm{O}_{3}$. In this regard, cross check of different measurement techniques is important. Formation and the type of $\mathrm{N}_{x} \mathrm{O}_{y}$ depends strongly on the operation conditions such as oxygen content [7], polarity, humidity, SIE, presence of catalyst [18] or VOC $[19,20]$, dielectric constant [21], temperature and so on. This trade-off between VOC removal and NOx formation restricts the possible energy input to the plasma reactor. Although the presence of catalyst changes the $\mathrm{NO} x$ formation, it is still difficult to suppress them completely. NO $x$ decomposition by plasma is known to be possible only if the oxygen content is less than about $4 \%[22,23]$, which is unreal for the exhaust gas containing VOC. In the case of gliding arc discharge, the concentration of $\mathrm{NO}_{2}$ reaches up to several thousand ppm [20]. Kuroki et al. reported NO $x$ formation problem from the decomposition of adsorbed xylene on zeolite using AC barrier discharge plasma in air [24]. Microwave (MW) plasma is also known to produce high concentration of $\mathrm{NO}$ and $\mathrm{NO}_{2}(\sim 4000 \mathrm{ppm})$ when it is operated at air-like mixture [25]. The common factor for these two methods is high specific input energy up to several tens $\mathrm{kJ} \mathrm{L}^{-1}$. In this regards, suitable application of MW, RF or gliding arc plasmas will be the decomposition of persistent chemicals with relatively high concentration [26].

Figure 6 shows the formation of oxides of nitrogen $\left(\mathrm{N}_{x} \mathrm{O}_{y}\right)$ in plasma-driven catalyst reactors packed with different catalysts. Most abundant species of nitrogen oxides was $\mathrm{NO}_{2}$ and $\mathrm{NO}$ was negligible. The formation of $\mathrm{NO}_{2}$ showed a quadratic function of the SIE. Ag loaded zeolites (HY and MOR) exhibited slightly lower $\mathrm{NO}_{2}$ formation compared to those with $\gamma-\mathrm{Al}_{2} \mathrm{O}_{3}$ or $\mathrm{TiO}_{2}$. Nitrous oxide $\left(\mathrm{N}_{2} \mathrm{O}\right)$ is most stable molecules among nitrogen oxides. Humidity slightly reduced $\mathrm{N}_{2} \mathrm{O}$ formation, which has been also reported by other studies [27]. $\mathrm{N}_{2} \mathrm{O}$ is most stable

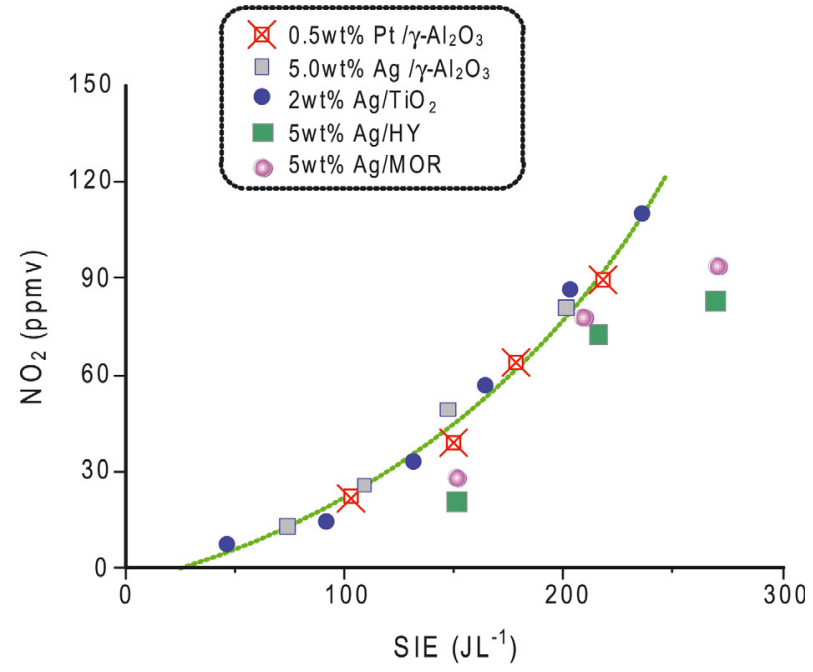

(a)

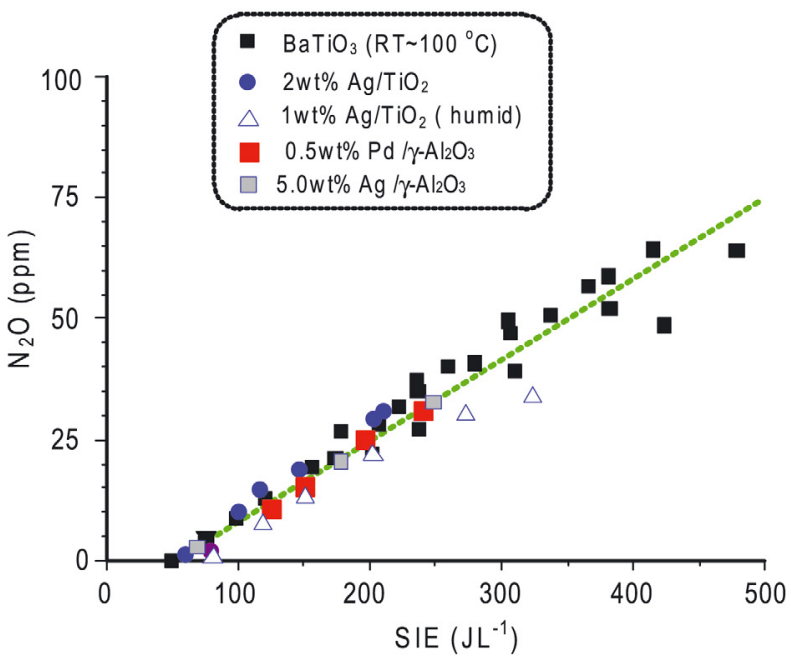

(b)

Fig. 6. Formation of nitrogen oxides $\left(\mathrm{N}_{x} \mathrm{O}_{y}\right)$ in plasma processing in air. (a) $\mathrm{NO}_{2}$ formation. (b) $\mathrm{N}_{2} \mathrm{O}$ formation.

form in $\mathrm{N}_{x} \mathrm{O}_{y}$ so its removal is even more difficult. It is possible to decompose $\mathrm{N}_{2} \mathrm{O}$ to $\mathrm{N}_{2}$ in reducing gas mixtures, but hard to decompose or oxidize $\mathrm{N}_{2} \mathrm{O}$ in air-like mixture. Regardless of the type of packing material, the formation of $\mathrm{N}_{2} \mathrm{O}$ in dry air is a linear function of SIE as shown in Figure 6b.

$$
\left[\mathrm{N}_{2} \mathrm{O}\right]_{p p m}=0.17 \times \mathrm{SIE}-7.9 .
$$

This equation may also be used for the rough estimation of the specific input energy to a plasma reactor.

\subsection{Cycled system}

The basic idea of the cycled system originates to the unique behavior of PDC system according to the oxygen content in gas mixture [28]. Figure 7 shows an example 


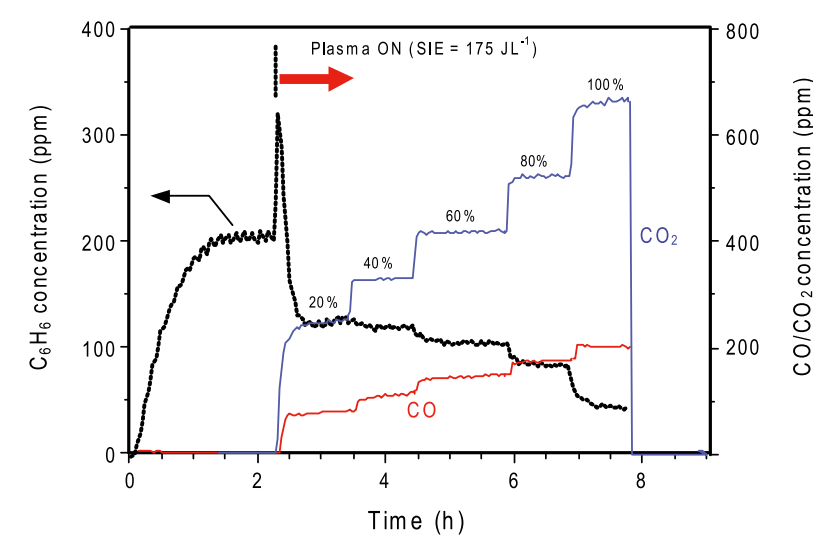

Fig. 7. Effect of oxygen content on the VOC decomposition using the plasma-catalyst reactor ( $5 \mathrm{wt} \% \mathrm{Cu} / \mathrm{MOR})$. Applied voltage and frequency were kept constant at $16 \mathrm{kV}$ and $300 \mathrm{~Hz}$, respectively. Temperature was $100{ }^{\circ} \mathrm{C}$. Space velocity was $33000 \mathrm{~h}^{-1}$.

how oxygen content influences the decomposition of benzene in the PDC reactor with $5 \mathrm{wt} \% \mathrm{Cu} / \mathrm{MOR}$ catalyst. When plasma was turned on after the adsorption saturation, a sharp peak of benzene appeared due to plasmainduced desorption and leveled off to certain level. Despite of the constant SIE, the concentration of benzene decreased as the $\mathrm{O}_{2}$ content increased. The resulting reaction products of $\mathrm{CO}$ and $\mathrm{CO}_{2}$ also increased with $\mathrm{O}_{2}$ content. The reaction immediately stopped as the plasma power was turned off. This highly $\mathrm{O}_{2}$-content dependent behavior does not appear in the conventional catalytic reaction or nonthermal plasma alone process [7]. The authors demonstrated complete oxidation of benzene using the $\mathrm{Ag} / \mathrm{TiO}_{2}$ catalyst and $\mathrm{O}_{2}$ plasma. Recently, Fan et al. reported the complete oxidation of benzene using cycled system [29]. They used Ag/HZSM-5 catalyst with $\mathrm{SiO}_{2} / \mathrm{Al}_{2} \mathrm{O}_{3}$ ratio of 360 . For the optimization of the cycled system, it is necessary to sort our which materials are beneficial in terms of adsorption capacity of VOC and catalytic activity under oxygen plasma. We focused on the zeolites, which have large surface area and characteristic pore sizes.

Figure 8 shows the schematic diagram of the cycled system. Cycled system consisted of two different cycles of adsorption and oxygen plasma. In the adsorption mode, VOCs are removed by adsorption onto the surface of catalyst in the absence of plasma application. When the catalyst bed reached adsorption equilibrium, then the gas flow was switched to the other catalyst bed to sustain the VOC removal. The saturated catalyst bed is purged with oxygen, and then plasma is turned on to decompose the adsorbed VOCs. To assist the catalytic activity, some nanoparticles of active metals $(\mathrm{Ag}, \mathrm{Cu}, \mathrm{Zr}$ ) other than noble metals $(\mathrm{Pt}, \mathrm{Pd})$ are loaded on the surface of zeolite. A small additional PDC reactor was set downstream of the main $\mathrm{PDC}$ reactor to decompose the desorbed VOC just after the $\mathrm{O}_{2}$ plasma was turned on. In practical case, it will be beneficial to operate the regeneration mode in closed system after purging the catalyst bed with oxygen.
Adsorption mode (Plasm a OFF)

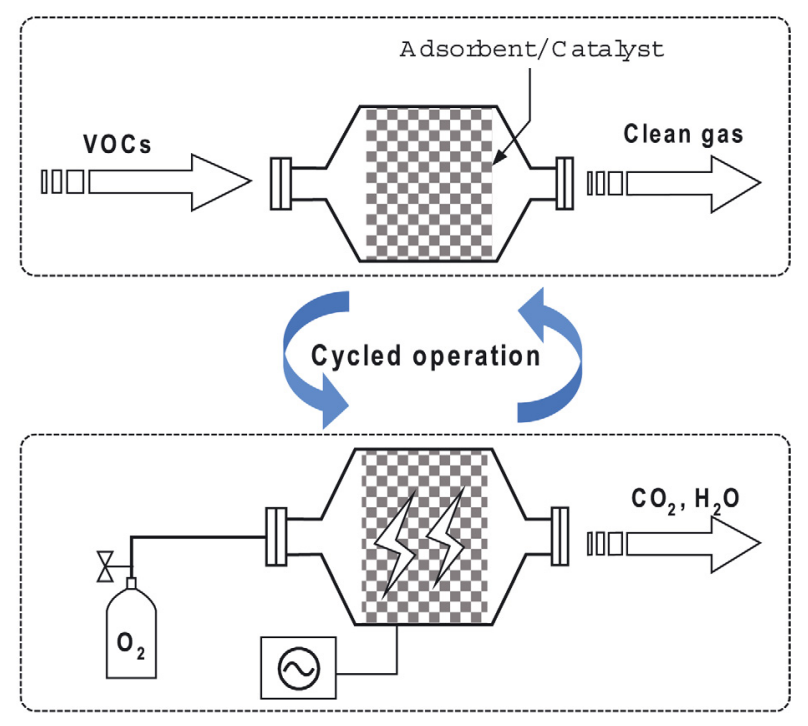

Regeneration mode (Plasma ON)

Fig. 8. Schematic diagram of cycled system.

For medium to small scale application, adsorption mode in daytime and regeneration mode in nighttime will be possible.

The operation of cycled system is quite similar to that in the conventional adsorption process. The main difference lies in the regeneration process. In conventional process, electrical heating or hot water vapor is supplied to the adsorbent bed for desorption of the VOC. The resulting highly concentrated VOC needs to be treated by catalytic oxidation or thermal oxidation. In the cycled system, the $\mathrm{O}_{2}$ plasma decomposition of adsorbed VOC and the regeneration of adsorbent occur simultaneously. The highly oxygen content dependent behavior of PDC can enhance energy efficiency. The formation of nitrogen oxides can be also avoided since the plasma is only turned on under oxygen environment. The major advantages of the cycled system can be summarized as follows.

(1) $\mathrm{O}_{2}$ plasma exhibits higher energy efficiency than that of air plasma.

(2) Free from nitrogen oxides formation.

(3) High $\mathrm{CO}_{2}$ selectivity (100\% for benzene decomposition using $\mathrm{Ag} / \mathrm{TiO}_{2}$ ).

(4) Compact system due to the concentration of dilute VOC with a large volume to a limited space (on the surface of catalyst).

(5) Rapid start-up and shut-down.

(6) High power operation is possible (same reason in 2).

(7) Adaptability to the change of concentration and flow rate.

Optimizing the cycled system requires two different properties of adsorption capacity and catalytic activity at high oxygen content. We focused on zeolites due to their large BET surface area, characteristic pore size. Some metal nanoparticles were loaded on the zeolites to enhance the catalytic activity. Figure 9 shows the adsorption breakthrough curves for the different catalysts. Among the 
H.-H. Kim and A. Ogata: Nonthermal plasma activates catalyst: from current understanding and future prospects

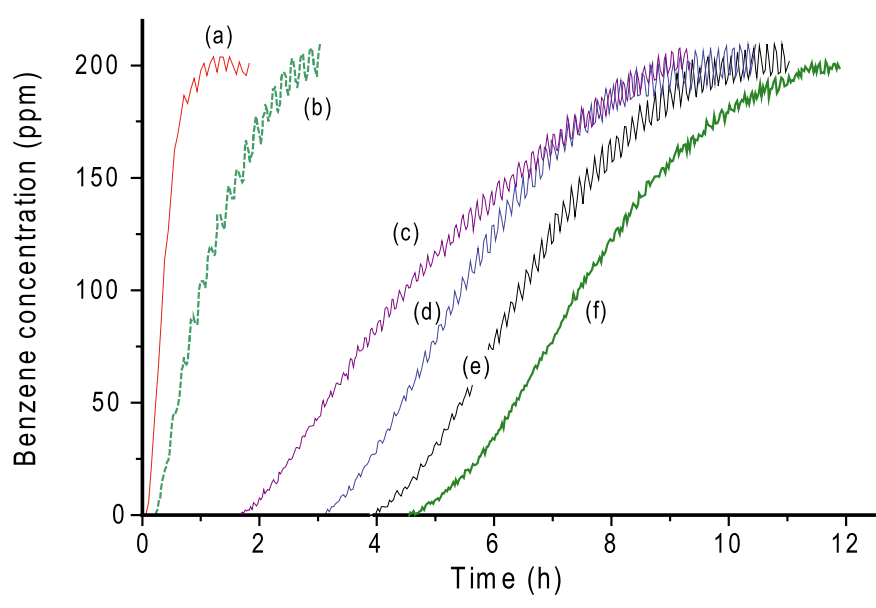

Fig. 9. Adsorption capacity of different catalyst at $100{ }^{\circ} \mathrm{C}$; (a) 2 wt $\% \mathrm{Ag} / \mathrm{TiO}_{2}$, (b) 5 wt $\% \mathrm{Ag} / \mathrm{MOR}$, (c) 10 wt $\% \mathrm{Ag} / \mathrm{HSY}$ (d) $5 \mathrm{wt} \% \mathrm{Ag} / \mathrm{MS}-13 \mathrm{X}$, (e) $5 \mathrm{wt} \% \mathrm{Ag} / \mathrm{HY}$, (f) $10 \mathrm{wt} \%$ $\mathrm{Ag} / \mathrm{NaY}$. Space velocity was $33000 \mathrm{~h}^{-1}$ except for (a) $2 \mathrm{wt} \%$ $\mathrm{Ag} / \mathrm{TiO}_{2}\left(S V=22000 \mathrm{~h}^{-1}\right)$.

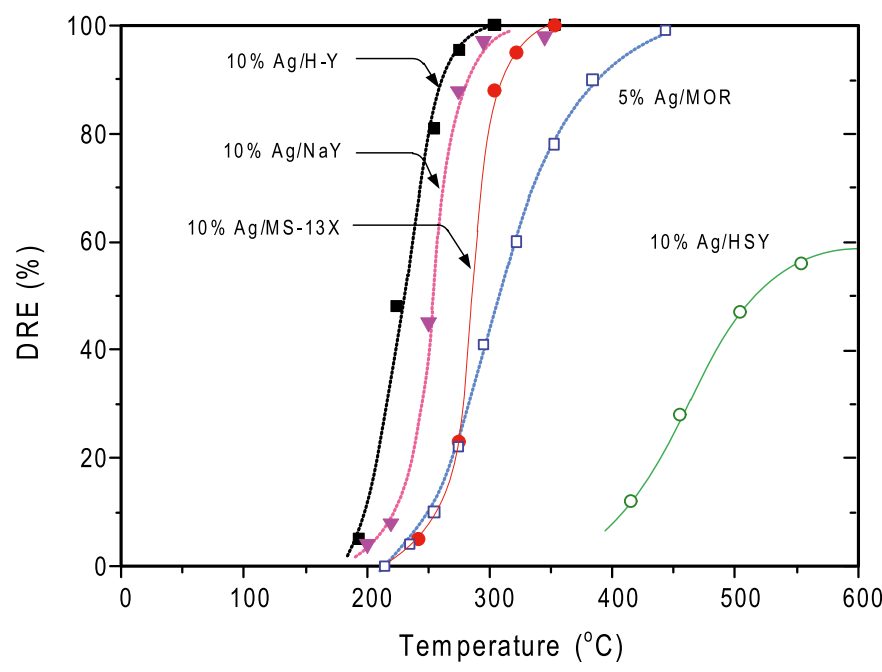

Fig. 10. Thermal catalysis of various zeolite catalysts $\left([\text { Benzene }]_{0}=150 \mathrm{ppm}\right.$, catalyst $=3.1 \mathrm{~cm}^{3}$, gas flow rate $=1$ LPM, plasma off).

tested zeolites, adsorption capacity was roughly proportional to the surface area and pore size; NaY $>$ MS-13X $(10 \AA) \approx \mathrm{HY}(7.4 \AA) \gg \operatorname{MOR}(6.7-7.0 \AA)>$ ferrierite (4.3-5.5 $\AA$, not shown). Since the tested zeolites had larger pore size than the molecular size of benzene (5.9 $\AA$ ), benzene is expected to be adsorbed dominantly inside the micro-channels. As expect, $\mathrm{TiO}_{2}$ exhibited small adsorption capacity compared to those with the zeolites.

Figure 10 summarizes the catalytic activity of Ag supported zeolites without plasma application. For the most catalyst (except for the high silica Y zeolite) decomposition of benzene started at above about $200{ }^{\circ} \mathrm{C}$ and reached to $50 \%$ decomposition with only further heating of about $50{ }^{\circ} \mathrm{C}$. Only $\mathrm{CO}$ and $\mathrm{CO}_{2}$ were detected as decomposition products. The activity of $\mathrm{Ag}$ supported catalysts in the conventional thermal process was in the following order; $\mathrm{HY}>\mathrm{NaY}>\mathrm{MS}-13 \mathrm{X}>\mathrm{MOR} \gg \mathrm{HSY}$.

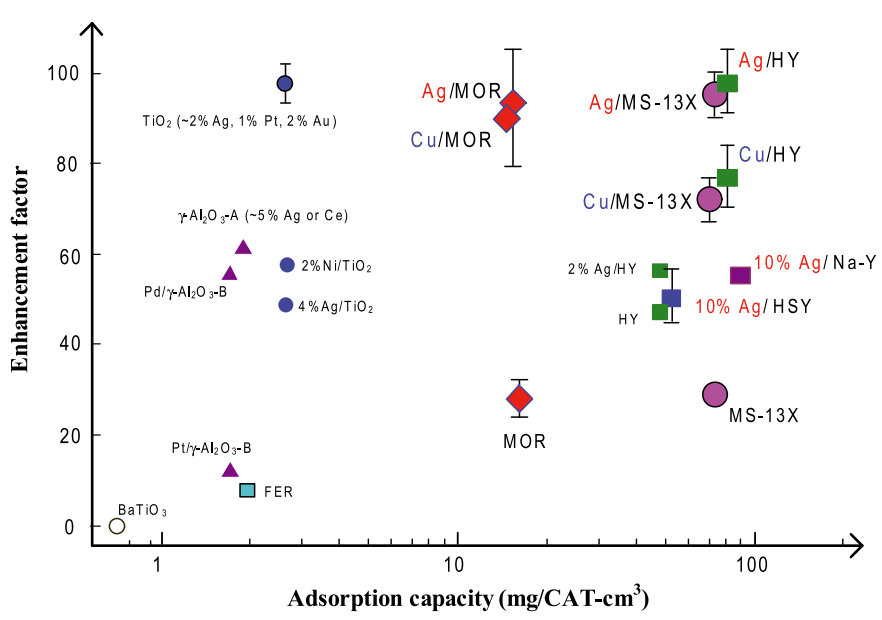

Fig. 11. Catalyst mapping in terms of enhancement factor (EF) and adsorption capacity of benzene $\left(100{ }^{\circ} \mathrm{C}, 200 \mathrm{ppm}\right.$ benzene) [7].

Figure 11 shows the catalysts mapping based on adsorption capacity and enhancement factor, which are essential parameters for the cycled system. The enhancement factor $(\mathrm{EF})$ is determined from the ratio of DRE at different $\mathrm{O}_{2}$ partial pressure.

$$
\text { Enhancement factor }=\frac{\mathrm{DRE}_{\text {Oxygen }}-\mathrm{DRE}_{\text {Air }}}{\left[\mathrm{O}_{2}\right]_{\text {Oxygen }}-\left[\mathrm{O}_{2}\right]_{\text {Air }}} \times 100
$$

where $\mathrm{DRE}_{\text {Oxygen }}$ and $\mathrm{DRE}_{\mathrm{Air}}$ indicate the decomposition-removal efficiency in oxygen and air, respectively. Catalysts with high EF values indicate proper catalyst in the cycled system. In contrast to the large enhancement factor, the $\mathrm{Ag} / \mathrm{TiO}_{2}$ catalyst has small adsorption capacity of about $2 \mathrm{mg}-\mathrm{C}_{6} \mathrm{H}_{6} / \mathrm{CAT}-\mathrm{cm}^{3}$, which make less attractive to be used in the cycled system. On the other hand, most of zeolites have relatively large specific surface area so that they can be served as good adsorbents. It is interesting to note that the loading of $\mathrm{Ag}$ or $\mathrm{Cu}$ nanoparticles on zeolites enhanced the EF values by a factor of about 3. This performance enhancement can partly be explained by the increase in the surface area by the small sizes of the metal nanoparticles. For the tested zeolites, $\mathrm{Ag}$ exhibited slightly larger $\mathrm{EF}$ values than those with $\mathrm{Cu}$. The large adsorption capacity together with the high catalytic activity provides high potential of the cycled system to be applied in the real emission sites.

It is worth to note that the EF does not simply follow the order of catalytic activity in the conventional thermal catalysis (i.e. without plasma application). The $10 \mathrm{wt} \%$ $\mathrm{Ag} / \mathrm{NaY}$ had higher catalytic activity than that of $10 \mathrm{wt} \%$ $\mathrm{Ag} / \mathrm{MS}-13 \mathrm{X}$ in the thermal catalysis, but the EF values are reversed. On the other hand, the HSY exhibited poor activity both in thermal catalysis and the cycled system.

\subsection{Surface plasma observation using microscope-ICCD camera}

To study the fundamental mechanism, metal nanoparticles supported zeolites were also evaluated in terms of 


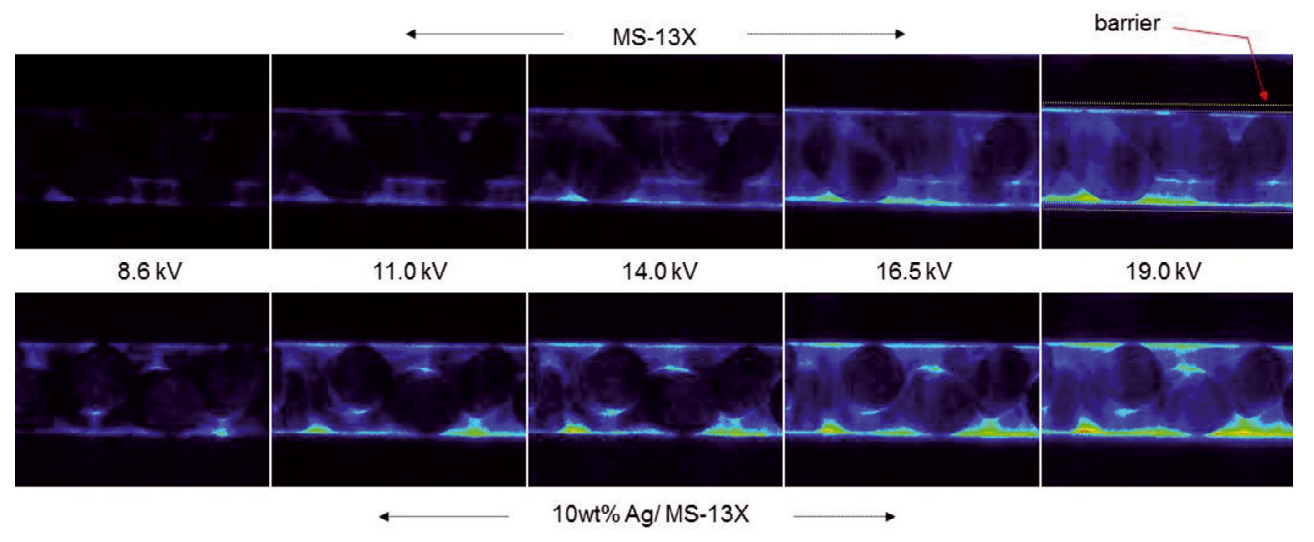

Fig. 12. ICCD camera snapshots of the discharge plasma over molecular sieve $13 \mathrm{X}$ zeolite (MS-13X) with or without Ag loading; (frequency $=50 \mathrm{~Hz}, 2 \mathrm{X}$ lens, $2 \mathrm{~mm}$ gap, exposure time $=100 \mathrm{~ms}$ ).

physical- and electrical aspects. A microscope-ICCD camera was applied to observe the plasma generation on the surface of zeolite. Figure 12 shows the ICCD camera photographs of the discharge plasma in the MS-13X zeolite packed barrier discharge reactor. Zeolite pellets were packed in a barrier discharge reactor, and the discharge plasma was observed from the top of the reactor. Discharge plasma was influenced not only by the applied voltage but also by the supported amount of Ag. The metal nanoparticles greatly changed the plasma generation on the surface of catalysts and the plasma onset voltage as well. When there was no metal loading, plasma generation was mostly confined to the vicinity of the zeolite pellets. The discharge is stronger when $10 \mathrm{wt} \%$ of $\mathrm{Ag}$ nanoparticles were loaded on the surface. Figure 13 shows enlarged photos showing how discharge plasma propagate on the surface of single catalyst pellet. The Ag nanoparticle helped the surface streamer to be expanded over a wide area. This change was also supported by the voltagecurrent waforms [30]. The number of microdischarges (i.e. surface streamers) increased with proportional to the loading amount of $\mathrm{Ag}$ nanoparticles, whereas the peak current values were decreased. It is interesting to note that the streamer-like discharge (surface streamer herein after) propagate in different shape compared to those in gas-phase. Streamer propagate in gas-phase in a straight manner according to the electric field. As indicated by arrows in Figure 13b, however, the propagation of surface streamers is not straight to the electric field, and divaricate randomly. Furthermore, memory effect due to charge accumulation on dielectrics (catalyst surface) was not observed. The surface streamers appeared randomly in terms of position and shape.

Figure 14 shows the discharge images by the ICCD camera with different magnification and exposure time for the $\mathrm{BaTiO}_{3}$-packed plasma reactor. Unlike the zeolites packed cases, surface streamers were not observed in the $\mathrm{BaTiO}_{3}$-packed reactor. Discharge plasma was first appeared with several plasma spots at the contact points of $\mathrm{BaTiO}_{3}$ beads, which is also referred to as partial discharge [31]. The number, the size and the luminescence of

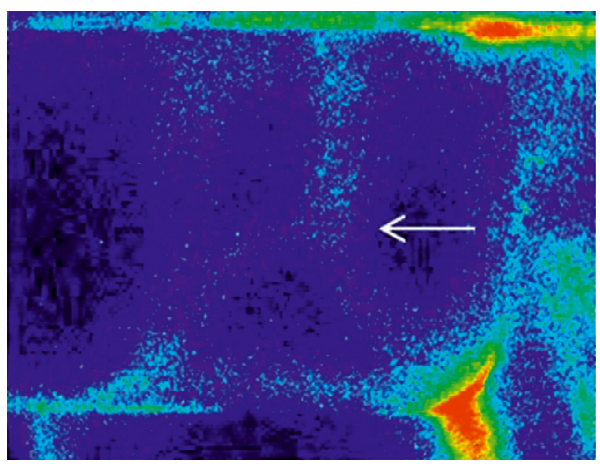

(a)

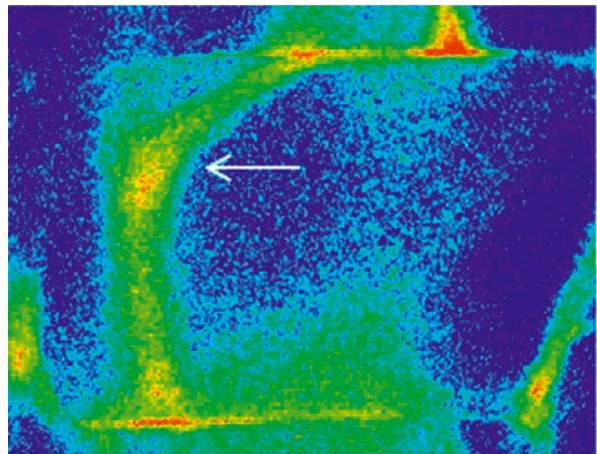

(b)

Fig. 13. ICCD camera images of discharge propagation on the surface of MS-13X zeolites $(19 \mathrm{kV}, 50 \mathrm{~Hz}$, DBD reactor with $4 \mathrm{~mm}$ gap, 5X lense). Exposure time was $40 \mathrm{~ms}$. (a) MS-13X. (b) $10 \mathrm{wt} \% \mathrm{Ag} / \mathrm{MS}-13 \mathrm{X}$.

plasma spots increased as the applied voltage increased. The expansion of plasma area was only observed on the surface of glass barrier, but not on the surface of $\mathrm{BaTiO}_{3}$ beads. These ICCD camera images are consistent with the digital camera images [32]. The potential $\mathrm{BaTiO}_{3}$ as catalyst is limited because of its small surface area. Although the packing of $\mathrm{BaTiO}_{3}$ beads reduces the corona onset voltage, it does not make plasma to be expanded 
H.-H. Kim and A. Ogata: Nonthermal plasma activates catalyst: from current understanding and future prospects
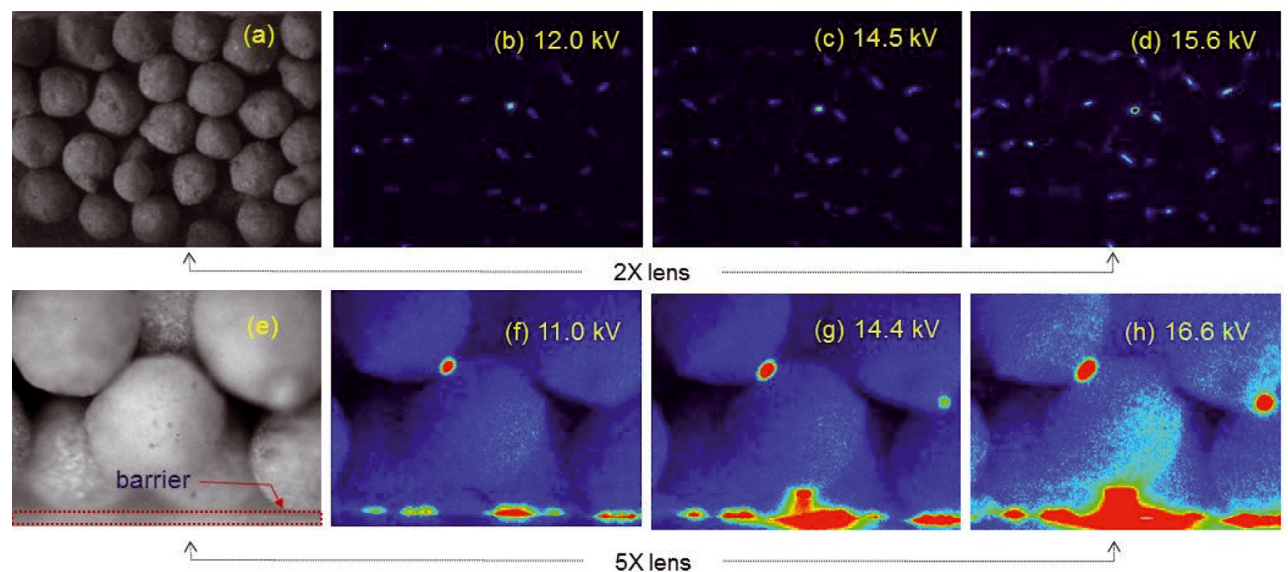

Fig. 14. ICCD camera images of discharge plasma in the $\mathrm{BaTiO}_{3}\left(\varepsilon_{s}=10000\right)$ packed bed reactor; (a)-(d) $40 \mathrm{~ms}$ exposure time, gain $=64 ;(\mathrm{e})-(\mathrm{f}) 500 \mathrm{~ms}$ exposure time, gain 70 .

on the surface. In other words, the microdischarges in the $\mathrm{BaTiO}_{3}$-packed reactor are produced within limited volume in contrast to the zeolite catalysts-packed plasma reactor.

\subsection{Plausible mechanism}

Plasma chemistry consists of complex physical and chemical process, so the clear understanding of overall processes still remain elusive. The chemical reaction in plasmacatalyst process is even more difficult to understand, since it contains interactions between them together with elementary steps in each processes. Nevertheless, there have been many papers reporting the synergetic effects in the single-stage plasma-driven catalyst system [33]. Figure 15 summarizes the current understanding of synergy effect in the complementary combination of plasma with catalyst. The most common finding in the synergistic effects is the better $\mathrm{CO}_{2}$ selectivity (i.e. low CO formation) [34-37]. Despite the similar reaction conditions, different catalysts lead to different $\mathrm{CO}_{2}$ selectivity indicating the important role of catalytic reaction. Two different mechanisms are expected to occur separately or simultaneously [19]. One is the change of reaction pathway which leads preferentially to $\mathrm{CO}_{2}$. Formic acid $(\mathrm{HCOOH})$ is a common intermediate from aromatic VOCs [14]. The loading of metal catalysts produces less or no $\mathrm{HCOOH}$. The other one is re-oxidation of $\mathrm{CO}$ into $\mathrm{CO}_{2}$ on the metal nanoparticles supported on catalyst. Ozone-assisted catalytic oxidation of carbon monoxide (CO) has been reported in 1921 just after the world war I [38]. Silver and manganese oxide $\left(\mathrm{MnO}_{2}\right)$ were found to be effective in the $\mathrm{CO}$ oxidation with ozone. Direct $\mathrm{CO}$ oxidation by silent discharge was also tested but less efficient. Similar effects in $\mathrm{CO}$ oxidation have been also reported for $\mathrm{CeO}_{2}$ [39] and $\mathrm{Au} / \mathrm{ZrO}_{2}$ [40] at temperature range of $20-80{ }^{\circ} \mathrm{C}$. As shows in the previous Section (4.4), the packing of catalytic materials in plasma reactors also changes physical-/electrical characteristics of plasma generation; (1) decrease in plasma onset voltage, (2) increase the number of microdischarge, (3) extension

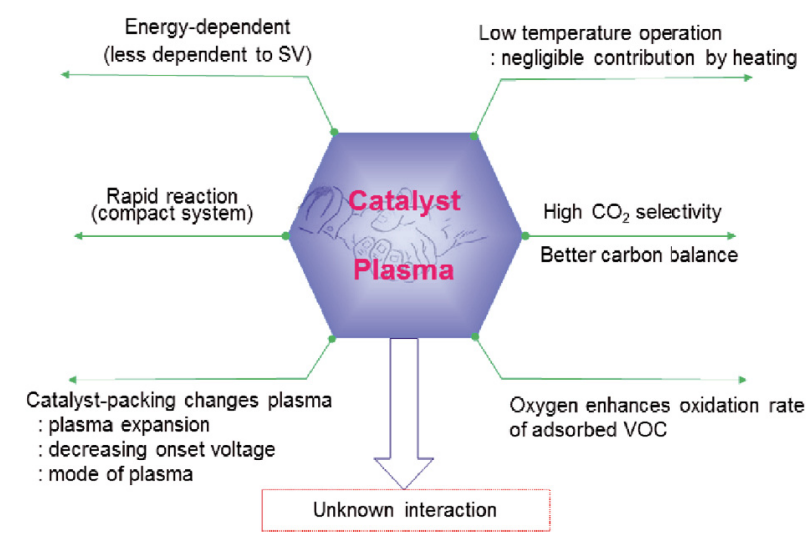

Fig. 15. Synergistic effects in the complementary combination of nonthermal plasma with catalyst.

of plasma area by loading metal nanoparticles on the surface. The reason for the plasma onset with low voltage has been well explained by the electric field augmentation by the high dielectric constant of packing catalysts compared to air. The number of microdischarge is due to both partial discharge between the catalyst and surface discharge on the surface of catalyst. The electric field may be enhanced near the well-dispersed metal nanoparticles, which in turn helps plasma to be expanded over the surface [30]. This physical factor was found to be correlated with the chemical effect of catalyst (i.e. catalytic activity). For example, $\mathrm{Ag}$ has better catalytic activity than $\mathrm{Cu}$, which is consistent with the trend in plasma expansion.

The combination of nonthermal plasma with Titanium dioxide $\left(\mathrm{TiO}_{2}\right)$ was first applied for $\mathrm{NO} x$ removal $[41,42]$, then later for the indoor air [43] and VOC [44]. According to the influence of precedent UV-photocatalyst studies at that time, UV was expected to play an important role in the plasma-driven catalytic process as well as the high energy electrons, excited molecules and radicals. Table 2 compares some of key parameters between UV-photocatalyst and plasma-driven catalysis in the application of VOC control. Space velocity in the 
The European Physical Journal Applied Physics

Table 2. Comparison of major parameter between UV-photocatalyst and plasma-driven catalysis.

\begin{tabular}{ccc}
\hline Parameter & Plasma-driven catalysis (PDC) & UV-photocatalyst \\
\hline Space velocity & $\sim 10^{4} \mathrm{~h}^{-1}$ & $<10^{2} \mathrm{~h}^{-1}$ \\
(GHSV) & & \\
Concentration & several hundred ppmv & several tens ppmv \\
UV dose & $\sim$ several $\mu \mathrm{W} / \mathrm{cm}^{2}$ & $\sim$ several tens $\mathrm{mW} / \mathrm{cm}^{2}$ \\
Reactor geometry & Flexible & less flexible due to UV irradiation \\
\hline
\end{tabular}

UV-photocatalyst is normally $2-3$ orders of magnitude smaller than that in the PDC process. Furthermore, there is also similar degree of difference in the VOC concentration. Comparison of these two design parameters clearly indicates the potential of PDC process for the VOC removal. Recent studies, however, provided several experimental evidences that the role of UV in the PDC process is minor due to the low UV dose $[45,46]$. UV dose in photocatalytic process is in the order of several $\mathrm{mW} \mathrm{cm}^{-2}$, whereas it is only in the order of several $\mu \mathrm{W} \mathrm{cm}{ }^{-2}$ in nonthermal plasma in air. Wavelength resolved measurement of emission spectrum of DC plasma jet in $\mathrm{N}_{2}$ also indicated that UV radiation ranged in the order of $\mathrm{nW}$ [47]. UV dose even in the outdoor shade in the daytime reaches several hundred $\mu \mathrm{W} \mathrm{cm}{ }^{-2}[48]$. Lu and Laroussi studied the influence of gas mixture on UV emission and reported $800 \mu \mathrm{W} \mathrm{cm} \mathrm{cm}^{-2}$ as maximum value in $90 \% \mathrm{He}-10 \% \mathrm{~N}_{2}$ mixture [49]. They also showed that the presence of oxygen more than $1 \%$ greatly reduces the UV emission. These sets of data lead to a conclusion that the activation of surface by UV is negligible in the PDC process due to the low UV dose from the discharge plasma in air-like mixture.

The important role of oxygen content has been reported in the decomposition of VOC $[7,28,29]$. The increase of oxygen content in gas mixture not only enhances the decomposition efficiency of VOC but also increases the $\mathrm{CO}_{2}$ selectivity and carbon balance as well. On-line mass spectrometer analysis of isotope-labeled oxygen provided a direct evidence on the plasma induced fixation of oxygen on the surface of catalyst [50]. Plasma-induced fixation of oxygen and its involvement in surface chemical reaction was also experimentally demonstrated by the Guaitella et al. for the oxidation of $\mathrm{NO}$ to $\mathrm{NO}_{2}$ [51].

The position of catalyst is also important factor determining the overall efficiency. Some catalyst exhibits better performance in a two-stage configuration than in a single-stage configuration. There is in fair agreement with several independent works that ozone decomposition catalysts $\left(\mathrm{MnO}_{2}-\mathrm{CuO} / \mathrm{TiO}_{2}, \mathrm{Mn}_{2} \mathrm{O}_{3}, \mathrm{Ba}-\mathrm{CuO}-\mathrm{Cr}_{2} \mathrm{O}_{3} / \mathrm{Al}_{2} \mathrm{O}_{3}\right)$ favors two-stage stage configuration [52-54]. Beside the plasma expansion by the metal nanoparticle loading, an interesting way to generate plasma inside honeycomb configuration has been proposed and demonstrated. External DC electric field extracted plasma area to the inside of capillaries $[55,56]$. Since the PDC is operated far below the temperature window of thermal catalysis, direct interaction between NTP and the catalyst surface is the key factor to induce catalytic activity.
From engineering point of view, rapid start-up and shut-down is important for medium- or small-scale application. Since plasma can activate the catalyst even at room temperature, flick of a switch is enough to start-up the system and vice versa.

\section{Summary}

Complementary combination of nonthermal plasma with catalyst is gathering attentions for its merits over separate process. Current research trends and the state-of-theart knowledge have been outlined. For the optimization of cycled system, various metal nanoparticles supported zeolites were prepared and evaluated in terms of catalytic activity and the physic-chemical interaction. The loading of metal nanoparticles provided several interesting merits in the plasma-driven catalyst system. As chemical effects, the active metal nanoparticles enhanced the carbon balance and $\mathrm{CO}_{2}$ selectivity. The microscope-ICCD camera observation provided some interesting insight into how metal nanoparticle interacts with plasma. In addition to the chemical aspect, the supported metal nanoparticles expanded discharge plasma over wide areas on zeolites. The expansion of plasma area was also influenced by the loading amount of silver. The influence of metal nanoparticles on the plasma generation was also supported by the voltage-current characteristics. A positive correlation was found between the plasma generation pattern and the catalytic activity in the combined process. It is straightforward to increase the interaction between the plasma and zeolites as the area of plasma increases. Among tested active metals, silver showed the most prominent influence on the plasma generation. This physical property was also found to be highly correlated with the catalytic activity under plasma activation. Present knowledge on the interaction of NTP with catalyst clearly indicates that the optimization of the PDC process requires not only the investigation of chemical properties (catalyst activity, active surface species, reaction pathways etc.) but also the understanding of physical and electrical interaction of NTP with catalyst.

One difficult problem in the study of plasma-catalyst hybrid system is that the well-proven analysis instruments in the conventional catalytic research cannot be used unless significant modification is made. The main reasons are the high voltage and the electromagnetic noise from the plasma. The developed observation system using microscope-ICCD camera can also be used as a rough-butrapid evaluation tools for catalyst prior to the chemical 
H.-H. Kim and A. Ogata: Nonthermal plasma activates catalyst: from current understanding and future prospects

performance test in a plasma-driven catalyst reactor. Further collection of the fundamental information and the understanding the mechanism will accelerate the technical progress of the plasma-driven catalyst process working at atmospheric pressure and ambient temperature.

\section{References}

1. F.O. Anderegg, Trans. Am. Electrochemical Soc. 44, 203 (1923)

2. P.T. Newsome, J. Am. Chem. Soc. 48, 2035 (1926)

3. K.J. Boelter, J.H. Davidson, Aerosol Sci. Technol. 27, 689 (1997)

4. A. Yehia, A. Mizuno, Int. J. Plasma Environ. Sci. Technol. 2, 44 (2008)

5. A.A. Petrov, R.H. Amirov, I.S. Samoylov, IEEE Trans. Plasma Sci. 37, 1146 (2009)

6. J.M. Henis, Nitrogen oxide decomposition process. U.S. Patent 3,983,021, 1976

7. H.H. Kim, A. Ogata, S. Futamura, Appl. Catal. B: Environ. 79, 356 (2008)

8. M. Simek, M. Clupek, J. Phys. D: Appl. Phys. 35, 1171 (2002)

9. S. Yagi, M. Tanaka, J. Phys. D: Appl. Phys. 12, 1509 (1979)

10. B.M. Penetrante, M.C. Hsiao, B.T. Merritt, G.E. Vogtlin P.H. Wallman, IEEE Trans. Plasma Sci. 23, 679 (1995)

11. K. Yan, S. Kanazawa, T. Ohkubo, Y. Nomoto, T. IEE Japan 119-A, 731 (1999)

12. M.A. Jani, K. Takaki, T. Fujiwara, J. Phys. D: Appl. Phys. 32, 2560 (1999)

13. J. Jarrige, P. Vervisch, J. Appl. Phys. 99, 113303 (2006)

14. H.H. Kim, A. Ogata, S. Futamura, J. Phys. D: Appl. Phys. 38, $1292(2005)$

15. J.J. Spivey, Ind. Eng. Chem. Res. 26, 2165 (1987)

16. T. Yamamoto, streams. J. Hazard. Mater. B 67, 165 (1999)

17. T.J. Wallington, J.W. Hoard, M.P. Sulbaekandersen, M.D. Hurley, Y. Nakano, M. Kawasaki, Environ. Sci. Technol. 37, $4242(2003)$

18. Y.H. Song, S.J. Kim, K.I. Choi, T. Yamamoto, J. Electrostat. 55, 189 (2002)

19. S. Futamura, Z. Zhang, T. Yamamoto, IEEE Trans. Ind. Appl. 35, 760 (1999)

20. Z. Bo, J. Yan, X. Li, Y. Chi, K. Cen, J. Hazard. Mater. 166, 1210 (2009)

21. A. Ogata, N. Shintani, K. Mizuno, S. Kushiyama, T. Yamamoto, IEEE Trans. Ind. Appl. 35, 753 (1999)

22. S. Masuda, S. Hosokawa, X. Tu, K. Sakakibara, S. Kitoh, S. Sakai, IEEE Trans. Ind. Applicat. 29, 781 (1993)

23. K. Yan, S. Kanazawa, T. Ohkubo, Y. Nomoto, Plasma Chem. Plasma Proc. 19, 421 (1999)

24. T. Kuroki, K. Hirai, R. Kawabata, M. Okubo, T. Yamamoto, IEEE Trans. Ind. Applicat. 46, 672 (2010)

25. A. Rousseau, A. Dantier, L. Gatilova, Y. Ionikh, J. Ropcke, Y. Tolmachev, Plasma Sources Sci. Technol. 14, 70 (2005)

26. Y.P. I, Y.C. Liu, K.Y. Han, T.C. She, Environ. Sci. Technol. 38, 3785 (2004)

27. S. Futamura, Z. Zhang, G. Prieto, T. Yamamoto, IEEE Trans. Ind. Appl. 34, 967 (1998)

28. H.H. Kim, S.M. Oh, A. Ogata, S. Futamura, J. Adv. Oxid. Technol. 8, 226 (2005)
29. H.Y. Fan, C.S. Shi, X.S. Li, D.X. Zhao, Y. Xu, A.M. Zhu, J. Phys. D: Appl. Phys. 42, 225105 (2009)

30. H.H. Kim, J.H. Kim, A. Ogata, J. Phys. D: Appl. Phys. 42, 135210 (2009)

31. A. Mizuno, H. Ito, J. Electrostat. 25, 97 (1990)

32. H. Arai, A. Ogata, A. Yamasaki, H.H. Kim, Y. Yanagisawa, Kagaku Kougaku Ronbunsyu 36, 310 (2010)

33. H.L. Chen, H.M. Lee, S.H. Chen, M.B. Chang, S.J. Yu, S.N. Li, Environ. Sci. Technol. 43, 2216 (2009)

34. H.H. Kim, A. Ogata, S. Futamura, IEEE Trans. Plasma Sci. 34, 984 (2006)

35. C. Subrahmanyam, A. Renken, L. Kiwi-Minsker, Plasma Chem. Plasma Proc. 27, 13 (2007)

36. C. Ayrault, J. Barrault, N. Blin-Simiand, F. Jorand, S. Pasquiers, A. Rousseau, J.M. Tatibouet, Catal. Today 89, 75 (2004)

37. T. Hakoda, K. Matsumoto, A. Mizuno, T. Kojima, K. Hirota, Plasma Chem. Plasma Proc. 28, 25 (2008)

38. A.B. Ray, F.O. Anderegg, J. Am. Chem. Soc. 43, 967 (1921)

39. A. Naydenov, R. Stoyanova, D. Mehandjiev, J. Mol. Catal. A: Chemical 98, 9 (1995)

40. P. Konova, A. Naydenov, T. Tabakova, D. Mehandjiev, Catal. Commun. 5, 537 (2004)

41. H.H. Kim, S. Katsura, A. Mizuno, in NOx control using combination process of photocatalyst and discharge plasma, 2nd International Symposium on Non-Thermal Plasma Technology (ISNTPT-2) (Salvador, Brazil, 1997; Salvador, Brazil, 1997)

42. H.H. Kim, K. Tsunoda, S. Katsura, A. Mizuno, IEEE Trans. Ind. Appl. 35, 1306 (1999)

43. A. Mizuno, Y. Kisanuki, M. Noguchi, S. Katsura, S.H. Lee, Y.K. Hong, S.Y. Shin, J.H. Kang, IEEE Trans. Ind. Appl. 35, 1284 (1999)

44. D. Li, D. Yakushiji, S. Kanazawa, T. Ohkubo, Y. Nomoto, J. Electrostat. 55, 311 (2002)

45. T. Sano, N. Negishi, E. Sakai, S. Matsuzawa, J. Mol. Catal. A: Chemical, 235 (2006)

46. H.B. Huang, D.Q. Ye, M.L. Fu, F.D. Feng, Plasma Chem. Plasma Proc. 27, 577 (2007)

47. R. Oikari, V. Hayrinen, R. Hernbert, J. Phys. D: Appl. Phys. 35, 1109 (2002)

48. K. Hashimoto, H. Irie, A. Fujihsima, Jpn J. Appl. Phys. 44, 8269 (2005)

49. X. Lu, M. Laroussi, J. Appl. Phys. 98, 023301 (2005)

50. H.H. Kim, A. Ogata, M. Schiorlin, E. Marotta, C. Paradisi, Catal. Lett. 141, 227 (2011)

51. O. Guaitella, M. Hubner, S. Welzel, D. Marinov, J. Ropcke, A. Rousseau, Plasma Sources Sci. Technol. 19, 045206 (2010)

52. J.V. Durme, J. Dewulf, W. Sysmans, C. Leys, H.V. Langenhove, Appl. Catal. B: Environ. 74, 161 (2007)

53. H. Huang, D. Ye, X. Guan, Catal. Today 139, 43 (2008)

54. A. Ogata, K. Saito, H.H. Kim, M. Sugasawa, H. Aritani, H. Einaga, Plasma Chem. Plasma Proc. 30, 33 (2010)

55. S. Sato, K. Hensel, H. Hayashi, K. Takashima, A. Mizuno, J. Electrostat. 67, 77 (2009)

56. K. Hensel, S. Sato, A. Mizuno, IEEE Trans. Plasma Sci. 36, 1282 (2008) 